\title{
20(S)-Protopanaxadiol enhances angiogenesis via HIF-1 $\alpha$-mediated VEGF secretion by activating p70S6 kinase and benefits wound healing in genetically diabetic mice
}

\author{
Er-Yun Zhang ${ }^{1,2}$, Bo Gao ${ }^{1}$, Hai-Lian Shi ${ }^{1}$, Ling-Fang Huang ${ }^{1}$, Li Yang ${ }^{1}$, Xiao-Jun Wu ${ }^{1}$ and Zheng-Tao Wang ${ }^{1}$ \\ Impaired angiogenesis is one of the crucial factors that impede the wound healing process in diabetic foot ulcers (DFUs). In this \\ study, we found that 20(S)-protopanaxadiol (PPD), an aglycone of ginsenosides in Panax notoginseng, stimulated angiogenesis \\ and benefited wound healing in genetically diabetic mice. In HUVECs, PPD promoted cell proliferation, tube formation and \\ VEGF secretion accompanied by increased nuclear translocalization of HIF-1 $\alpha$, which led to elevated VEGF mRNA expression. \\ PPD activated both PI3K/Akt/mTOR and Raf/MEK/ERK signaling pathways in HUVECs, which were abrogated by LY294002 and \\ PD98059. Furthermore, these two pathways had crosstalk through p70S6K, as LY294002, PD98059 and p70S6K siRNA \\ abolished the angiogenic responses of PPD. In the excisional wound splinting model established in db/db diabetic mice, PPD \\ $\left(0.6,6\right.$ and $60 \mathrm{mg} \mathrm{ml}^{-1}$ ) accelerated wound closure, which was reflected by a significantly reduced wound area and epithelial \\ gaps, as well as elevated VEGF expression and capillary formation. In addition, PPD activated PI3K/Akt/ERK signaling pathways, \\ as well as enhanced p70S6K activity and HIF-1 $\alpha$ synthesis in the wounds. Overall, our results revealed that PPD stimulated \\ angiogenesis via HIF-1 $\alpha$-mediated VEGF expression by activating p70S6K through PI3K/Akt/mTOR and Raf/MEK/ERK signaling \\ cascades, which suggests that the compound has potential use in wound healing therapy in patients suffering from DFUs. \\ Experimental \& Molecular Medicine (2017) 49, e387; doi:10.1038/emm.2017.151; published online 27 October 2017
}

\section{INTRODUCTION}

Diabetic foot ulcers (DFUs) are the most common complication of diabetes mellitus with an annual incidence of $1-4 \%, 1$ and they account for $84 \%$ of all diabetes-related lower-leg amputations. $^{2}$ In addition to suffering from the disease, patients with DFUs often have a large healthcare burden and poor quality of life. ${ }^{3}$ Indeed, over the past few decades, the morbidity and disability of DFU have not decreased. ${ }^{4}$ Current therapy for diabetic wounds only achieves a 50\% healing rate that quite often has a temporary effect. ${ }^{4}$ Impaired angiogenesis is one of the crucial factors impeding the wound healing process in DFUs. ${ }^{5}$ Angiogenesis, an important molecular event in wound healing, 5,6 involves the growth of new blood vessels or neovascularization through nourishing the damaged tissues. Therefore, drugs facilitating angiogenesis often benefit the wound healing process in DFUs.
Vascular endothelial cells play a very important role in angiogenesis, and they contribute to the wound healing process. The vascular endothelial growth factor (VEGF) family of proteins facilitate angiogenesis by increasing vascular permeability and endothelial cell proliferation, migration and invasion into the surrounding tissues. ${ }^{7}$ Cellular responses to VEGF are mainly mediated by the receptor tyrosine kinase VEGFR2 (also known as Flk-1) on the surface of endothelial cells in a paracrine manner. ${ }^{8}$ Human umbilical vein endothelial cells (HUVECs) are isolated from the endothelium of veins of the umbilical cord and are used extensively as an in vitro model for angiogenesis research. ${ }^{9}$ The excisional wound splinting model is a widely used animal model for wound healing study in vivo in which the splint tightly adheres to the skin surrounding the wound and reduces wound closure due to skin contraction and wound dressings. ${ }^{10}$ The wound, therefore, heals through

\footnotetext{
${ }^{1}$ Shanghai Key Laboratory of Compound Chinese Medicines and The Ministry of Education (MOE) Key Laboratory for Standardization of Chinese Medicines, Institute of Chinese Materia Medica, Shanghai University of Traditional Chinese Medicine, Shanghai, China and ${ }^{2}$ Department of Pharmacognosy, China Pharmaceutical University, Nanjing, China

Correspondence: Dr X-J Wu or Dr Z-T Wang, Institute of Chinese Materia Medica, Shanghai University of Traditional Chinese Medicine, 1200 Cailun Road, Pudong District, Shanghai 201203, China.
}

E-mail: xiaojunwu320@126.com or ztwang@shutcm.edu.cn

Received 28 October 2016; revised 20 February 2017; accepted 18 April 2017 
granulation and re-epithelialization, a process similar to the one that occurs in humans. ${ }^{11}$

20(S)-protopanaxadiol (PPD) is one of the basic aglycones of dammarane type saponin within Panax notoginseng (Burk.) F.H. Chen, a famous tonic medicinal herb widely used in East Asia, which has been shown to benefit the relief of hemorrhages, blood stasis, blood circulation, bruises, swelling and pain. ${ }^{12}$ Ginsenosides such as Rb1, Rg3, Rg5 and notoginsenoside Ft1 have been shown to modulate angiogenesis and have the potential to be developed as angiotherapeutic agents. ${ }^{13-17}$ In contrast, ginsenoside CK has been shown to inhibit angiogenesis in HUVECs. ${ }^{18}$ Similar to ginsenoside CK, researchers suggested a few years ago that PPD could inhibit angiogenesis ${ }^{19}$ in HUVECs $\left(\mathrm{EC}_{50} \sim 5 \mu \mathrm{M}\right)$. However, in this study, we provided compelling evidence to demonstrate that when used at low concentrations, PPD promoted angiogenesis in HUVECs. It also facilitated wound healing of the excisional wound splinting model established in genetically diabetic $(d b / d b)$ mice. Further studies showed that PPD accelerated angiogenesis through HIF-1 $\alpha$-mediated VEGF secretion by activating both the PI3K/ Akt/mTOR and Raf/MEK/ERK signaling pathways and their downstream p70S6 kinase (p70S6K). Our findings re-examine the influence of PPD on angiogenesis and provide an alternative approach to relieve the suffering of patients with DFUs.

\section{MATERIALS AND METHODS}

\section{Compound}

PPD (purity $>98 \%$ ) was provided by the Shanghai R\&D Center for Standardization of Chinese Medicines (Shanghai, China). Its structure was confirmed by ${ }^{1} \mathrm{HNMR}$ and ${ }^{13} \mathrm{CNMR}$ spectral analysis.

\section{Cell culture and cell viability test}

HUVECs from ScienCell Research Laboratories were cultured in an endothelial cell medium (ECM, ScienCell, San Diego, CA, USA) supplemented with $5 \%$ fetal bovine serum (FBS, Gibco BRL, Gaithersburg, MD, USA), 100 units per ml penicillin and $100 \mu \mathrm{g} \mathrm{ml}-1$ streptomycin and $5 \% \mathrm{CO}_{2}$ at $37^{\circ} \mathrm{C}$. Cell viability after treatment with various concentrations of PPD in low $(5 \mathrm{~mm})$ or high $(30 \mathrm{~mm})$ glucose medium for $48 \mathrm{~h}$ was determined by 3-(4,5-dimethyl-2-thiazolyl)-2,5diphenyl-2-H-tetrazolium bromide (MTT) assay (Sigma-Aldrich). And the cell viability of the treated cells was presented as the percentage of the control viability.

\section{Tube formation assay}

After incubated with ECM containing 1\% FBS for $4 \mathrm{~h}$, HUVECs were seeded at a density of $1 \times 10^{4}$ cells per well in Matrigel (BD Biosciences, Bedford, MA, USA) coated 96-well plates followed by treatment with PPD at different concentrations for $4 \mathrm{~h}$. Tubes forming intact networks were quantified by counting the number of branch points from five random fields per well in a blind manner under an inverted microscope (Olympus CKX41, Tokyo, Japan).

\section{siRNA transfection}

HUVECs were cultured in 60-mm plates (for cell proliferation and tube formation) or $100-\mathrm{mm}$ plates (for western blotting analysis) without antibiotics overnight. When the cells reached $70-80 \%$ confluency, they were transiently transfected with $p 70 S 6 \mathrm{~K}$ siRNA and scramble siRNA (Genepharma, Shanghai, China) using lipofectamine
RNAiMAX according to the manufacturer's recommendations. For cell proliferation analysis, cells were treated with various concentrations of PPD for $48 \mathrm{~h}$. For tube formation assay, cells were treated with various concentrations of PPD for $4 \mathrm{~h}$. For western blotting analysis, cells were treated with PPD for the indicated time points.

\section{ELISA analysis}

HUVECs $\left(2 \times 10^{4}\right.$ cells per well) were cultured in ECM containing $1 \%$ FBS and treated with PPD for the indicated time points. VEGF secreted in the supernatant of the medium was examined with an ELISA kit (R\&D, Minneapolis, MN, USA) according to the manufacturer's manual. Optical density was measured at $450 \mathrm{~nm}$ using a microplate reader. Quantification of VEGF concentration was calculated by a standard curve plotted with recombinant human VEGF.

\section{Excisional wound splinting model}

Twelve-week-old female leptin receptor-deficient (Lepr $\mathrm{db} / \mathrm{JNju}$, $d b / d b)$ mice with high blood glucose $(25.3 \pm 7.7 \mathrm{~mm})$ were provided by the Nanjing Biomedical Research Institute of Nanjing University (Nanjing, China). The mice were single-house maintained under a $12 \mathrm{~h} \mathrm{light/dark} \mathrm{cycle} \mathrm{at} \mathrm{room} \mathrm{temperature}\left(23 \pm 2{ }^{\circ} \mathrm{C}\right)$ with free access to food and water. All animal experiments were conducted complying with the Guide for the Care and Use of Laboratory Animals, eighth edition (2011) (http:/grants.nih.gov/grants/olaw/guide-for-the-careand-use-of-laboratory-animals.pdf) and the Institutional Animal Care guidelines approved by the Experimental Animal Ethical Committee of Shanghai University of Traditional Chinese Medicine. The excisional wound splinting model was generated as described previously. ${ }^{10}$ Each wound was topically treated with $15 \mu$ l of PPD $(0.6,6$ and $60 \mathrm{mg} \mathrm{ml}^{-1}$ ) or PBS every other day for 14 days.

\section{Wound analysis}

The duration from the beginning of the wound formation to the time when the wound bed was re-epithelialized and filled completely with new tissue was defined as the time of wound closure. To compare the wound healing process, digital photographs of the wounds were taken every other day. Wound area was measured with a previously described method. ${ }^{20}$

\section{Histopathological examination}

For histological preparations, the skin was fixed in $10 \%$ formalin and then embedded in paraffin. Skin tissues were sectioned in $4-\mu \mathrm{m}$-thick slices for histopathological examination by hematoxylin/eosin (H\&E) staining.

\section{Real-time PCR}

RNA extraction, reverse transcription and real-time PCR reactions were performed as described previously. ${ }^{20}$ The sequences of the primers that were used are listed in Supplementary Tables S1 and 2. All of the messenger RNA (mRNA) expression data were normalized to the internal reference genes, which were GAPDH or $\beta$-actin, within the same samples.

\section{Western blotting analysis}

The western blotting analysis was conducted as described previously. ${ }^{20}$ The primary antibodies used were rabbit anti-VEGF (Abcam, Cambridge, UK), rabbit anti-CD31 (Abcam), rabbit anti-phospho-cRaf (Ser 338), -phospho-MEK1/2 (Ser 217 and Ser 221), -phosphoERK1/2 (Thr 202 and Tyr 204), -phospho-PI3K p85 (Tyr458), -phospho-Akt (Thr308), -phospho-mTOR (Ser2481), -phospho- 
p70S6K (Thr389), -c-Raf, -MEK1/2, -ERK1/2, -PI3K, -AKT, -mTOR, -p70S6K, and -HIF- $1 \alpha$, as well as $\beta$-actin (Cell Signaling Technology, Danvers, MA, USA). Primary antibody binding was detected using a peroxidase-conjugated secondary antibody (Pierce, Rockford, IL, USA). The blots were developed by ECL detection regents (GE Healthcare, Waukesha, WI, USA). The gray intensity of protein bands was quantified with ImageJ and normalized to that of $\beta$-actin or GAPDH in each sample.

\section{ChIP analysis}

HUVECs were cultured in ECM containing 1\% FBS and treated with PPD $(2.5 \mu \mathrm{M})$ for the indicated time periods. Soluble chromatin including the VEGF promoter region was isolated using the SimpleChIP plus enzymatic chromatin IP kit (Cell Signaling Technology), as described in the manufacturer's manual. Briefly, the cells were fixed with formaldehyde and lysed. Chromatin was harvested and subjected to immunoprecipitation using antibodies against HIF-1 $\alpha$ (Abcam). The DNA in the co-precipitated chromatin was extracted and used as a template for real-time PCR. The reaction was performed to amplify the VEGF promoter. The Ct value for HIF- $1 \alpha$ antibody captured DNA was normalized to that of the input DNA. Data were presented as fold enrichment over input DNA.

\section{In Vivo matrigel plug assay}

The Matrigel plug assay is a widely used method to test the in vivo proangiogenic effect of drugs. ${ }^{16}$ To examine the pro-angiogenic property of PPD, Matrigels $(0.5 \mathrm{ml})$ containing 20 units of heparin with PPD $(0,1$ and $2.5 \mu \mathrm{M})$ were injected subcutaneously into the ventral area of C57BL/6 mice (5 weeks old). After 7 days, the mice were killed, and the intact Matrigel plugs were collected and washed with PBS twice. Half of the Matrigel implants from each group were frozen immediately and lyophilized overnight to determine the hemoglobin content using Drabkin's reagent kit (Sigma). The remaining implants were subjected to immunohistochemical staining.

\section{Immunohistochemistry}

The sections were subjected to immunohistochemistry analysis according to a previously described method. ${ }^{20}$ The $\mathrm{CD} 31^{+}$vessel was stained using the rabbit anti-mouse CD31 antibody (Abcam) and peroxidase-conjugated goat anti-rabbit secondary antibody (Cell Signaling Technology). Images were obtained in four different
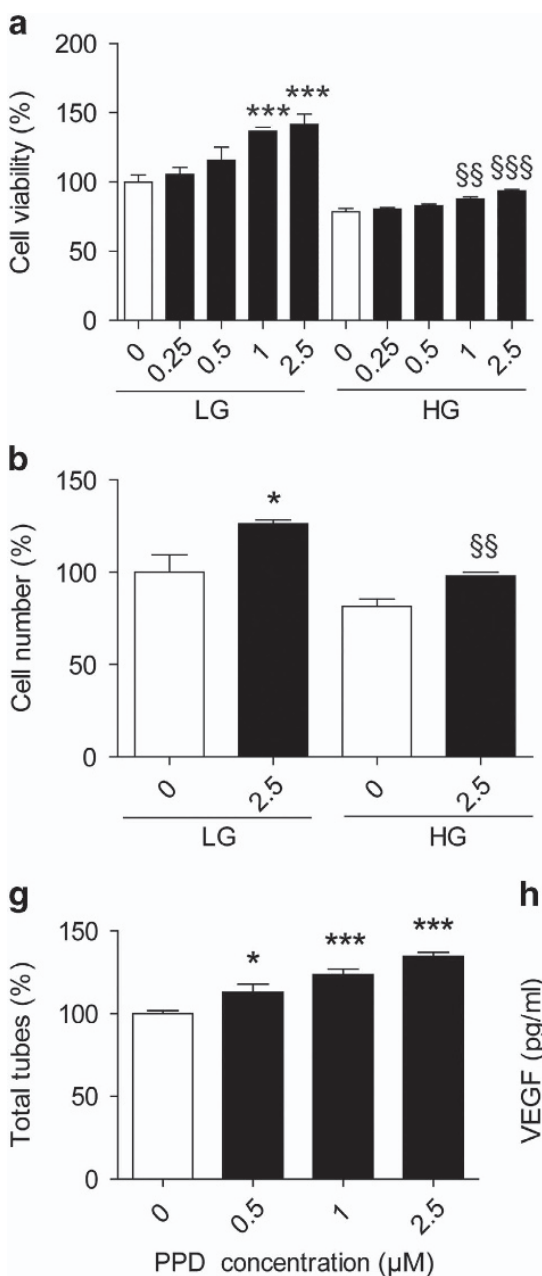

h
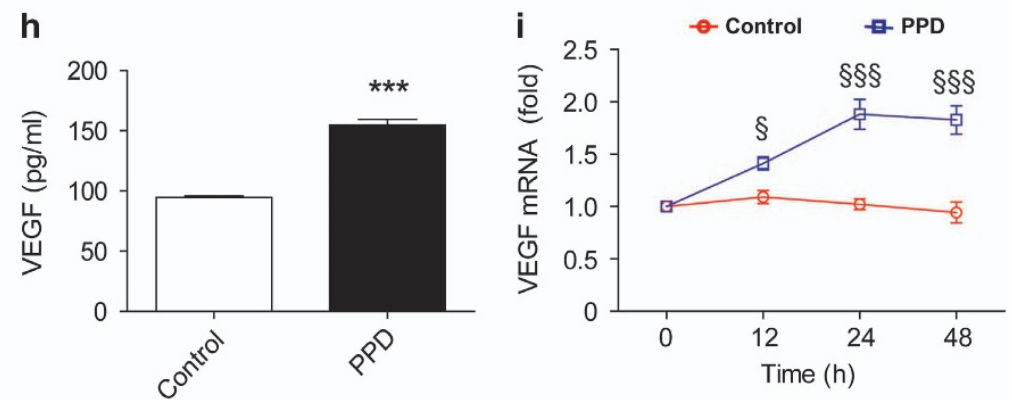

Figure 1 PPD stimulated angiogenesis in HUVECs. (a, b) Cell viability and cell number after treatment with PPD in low (5 mm, LG) and high (30 mM, HG) glucose medium for $48 \mathrm{~h}$. $n=6$ per group. (c-g) Tube formation after PPD treatment for $4 \mathrm{~h}$. (c) $0 \mu \mathrm{m}$, (d) $0.5 \mu \mathrm{m}$, (e) $1 \mu \mathrm{m}$, (f) $2.5 \mu \mathrm{m}$. (g) Bar graph of total tubes formed by PPD-treated cells (percentage to control). Control, white bars; PPD, black bars. $n=6$ /group. Scale bar $=200 \mu \mathrm{m}$. (h, i) VEGF secretion and mRNA expression after PPD treatment $(2.5 \mu \mathrm{m}) . n=5$ per group. ${ }^{*} P<0.05$, $* * * P<0.001$ versus control in low glucose medium; ${ }^{\S} P<0.05$, ${ }^{\S \S} P<0.001$ versus control in high glucose medium. 

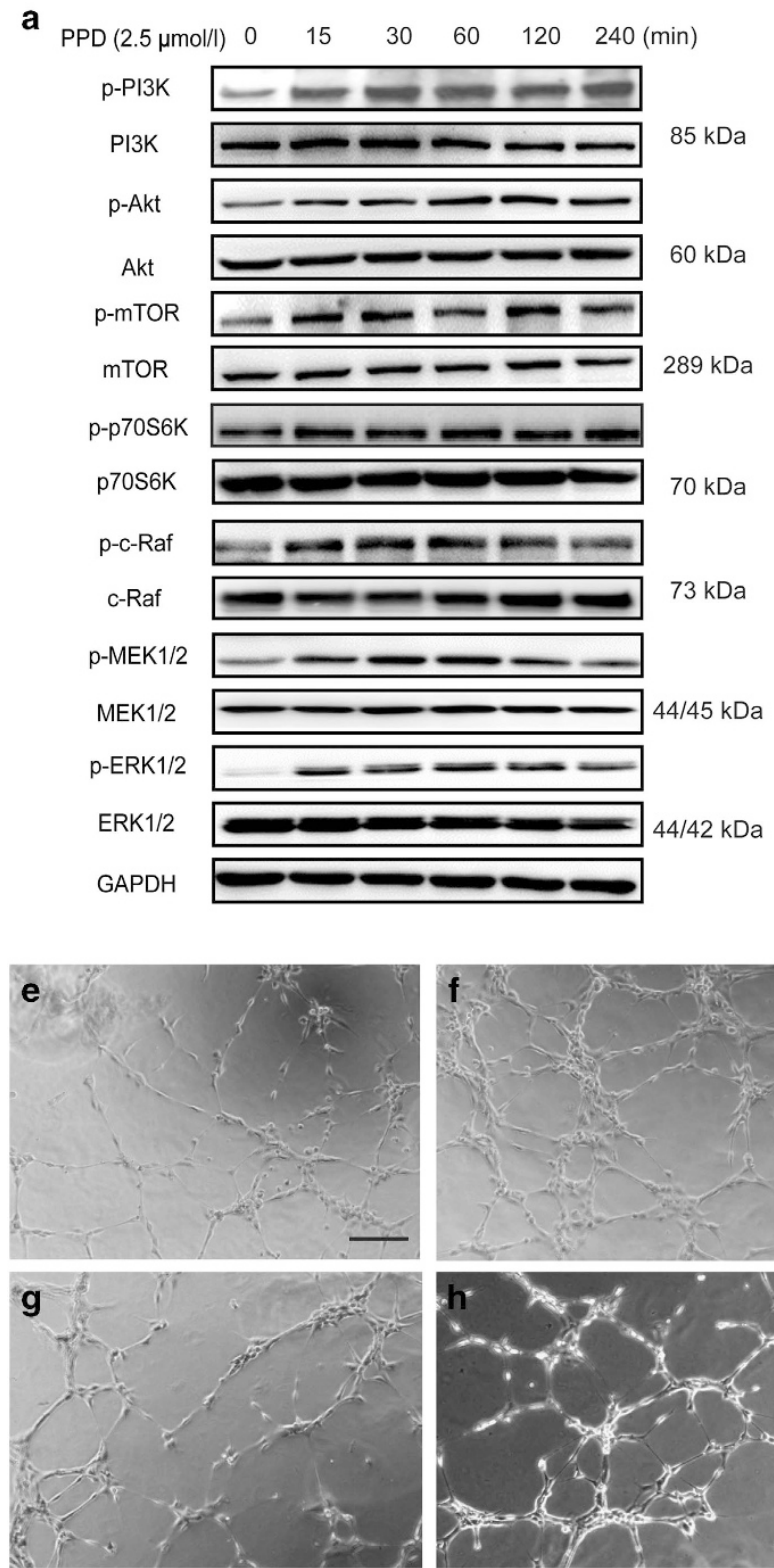
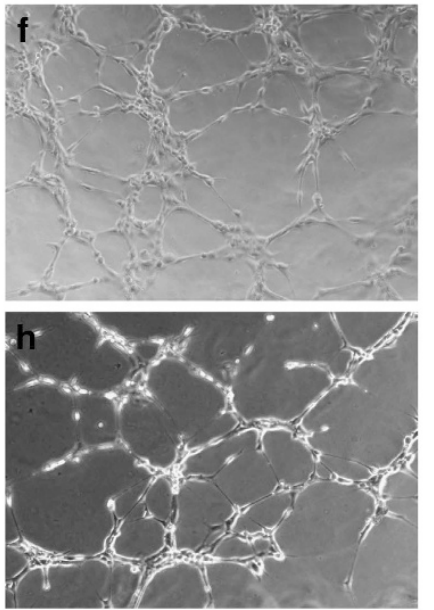

b

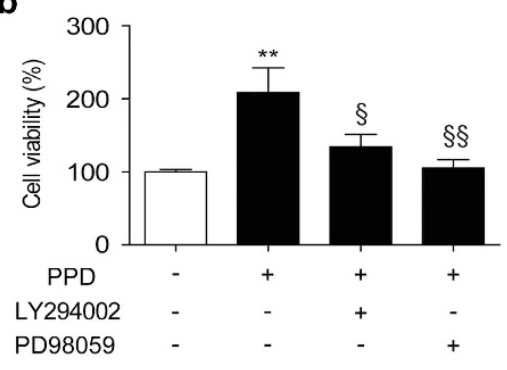

C
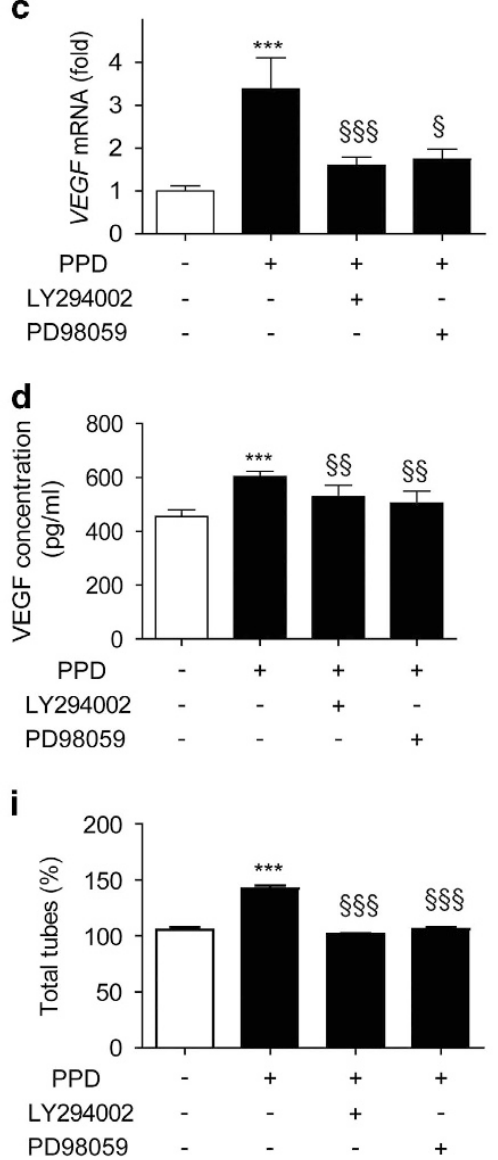

Figure 2 PI3K/Akt and Raf/MEK/ERK signaling pathways were required for PPD-stimulated angiogenic responses in HUVECs. (a) Expression of phospho-PI3K, -Akt, -mTOR, -p70S6K and -c-Raf, -MEK1/2, -ERK1/2 and $\beta$-actin in HUVECs stimulated with PPD for the indicated time period. (b) Cell viability following PPD stimulation for $48 \mathrm{~h}$ after pre-treatment with LY294002 or PD98059 for 30 min. $n=6$ per group. (c) VEGF mRNA expression after PPD stimulation for $24 \mathrm{~h}$ following pre-treatment with LY294002 or PD98059 for $30 \mathrm{~min}$. $n=6$ /group. (d) VEGF secretion after PPD stimulation for $48 \mathrm{~h}$ following pre-treatment with LY294002 or PD98059 for 30 min. $n=5$ per group. (e-h) Representative pictures of tube formation after PPD stimulation for $4 \mathrm{~h}$ following pre-treatment with LY294002 or PD98059 for 30 min. (e) Control; (f) PPD; (g) PPD+LY294002; (h) PPD+PD98059. Scale bar $=200 \mu$ m. (i) Tube formation activity after PPD stimulation for $4 \mathrm{~h}$ following pre-treatment with LY294002 or PD98059 for $30 \mathrm{~min}$. $n=5$ per group. ${ }^{* *} P<0.01$ and $* * * P<0.001$ versus control; ${ }^{\S} P<0.05,{ }^{\S \S} P<0.01$ and ${ }^{\S \S \S} P<0.001$ versus PPD only.

quadrants of each section and subjected to gray intensity statistics using ImagePro Plus software.

\section{Statistical analysis}

To examine the differences among multiple groups, one-way ANOVA followed by a Tukey's multiple comparison test was conducted with GraphPad Prism 5.0. An unpaired $t$-test was used to assess the differences between two groups. All data are presented as the mean \pm s.e.m. A value of $P<0.05$ was considered significantly different.

\section{RESULTS}

PPD induced angiogenic responses in HUVEC Cells

Consistent with a previous report, ${ }^{19} \mathrm{PPD}$ inhibited cell viability when used at $5 \mu \mathrm{M}$ in HUVECs (Supplementary Figure S1). However, when used at low concentrations from 0.25 to $2.5 \mu \mathrm{M}$, PPD treatment caused a concentration-dependent increase in the cell viability of HUVECs in either low ( $5 \mathrm{~mm}$ ) or high $(30 \mathrm{~mm})$ glucose medium, with a minimal effective 
a

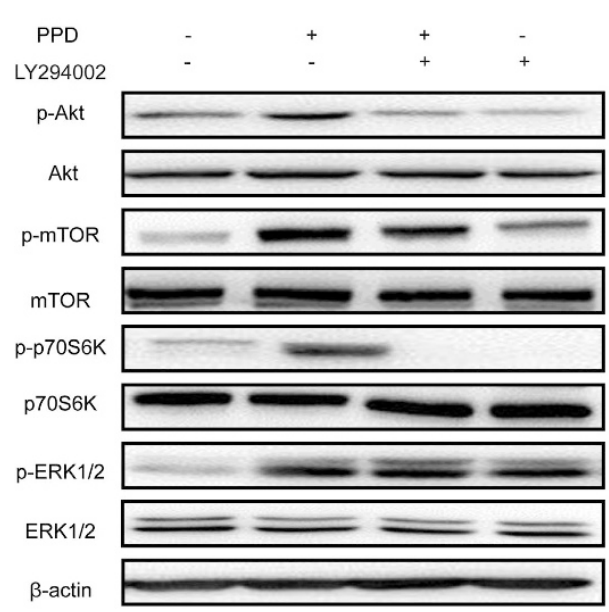

C

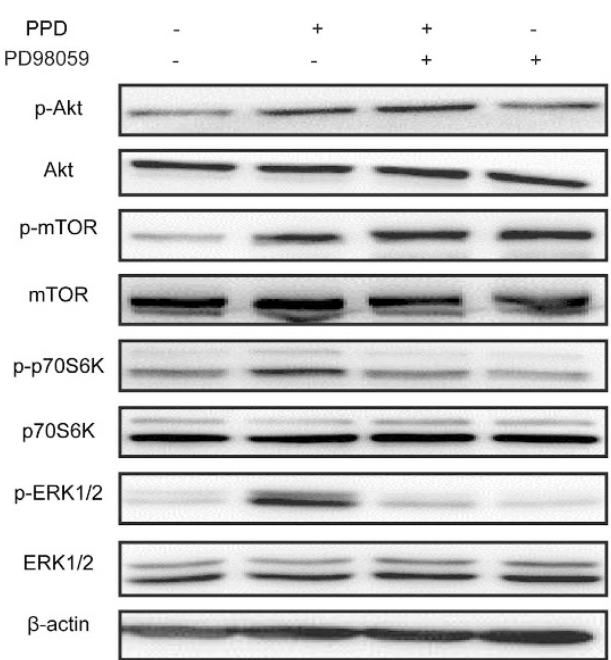

b
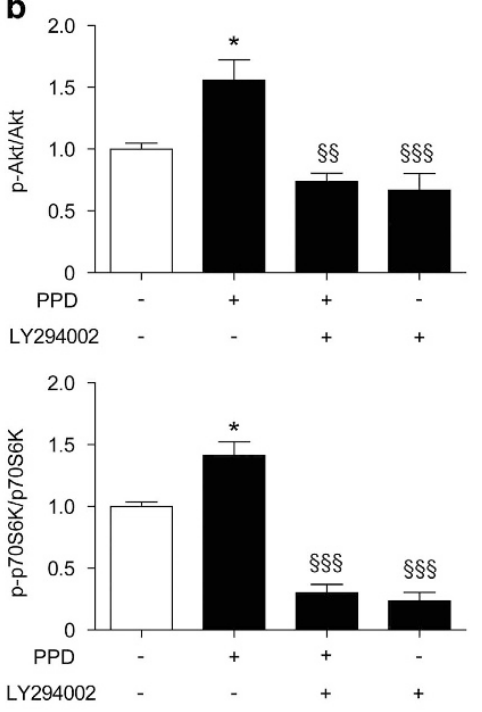

d
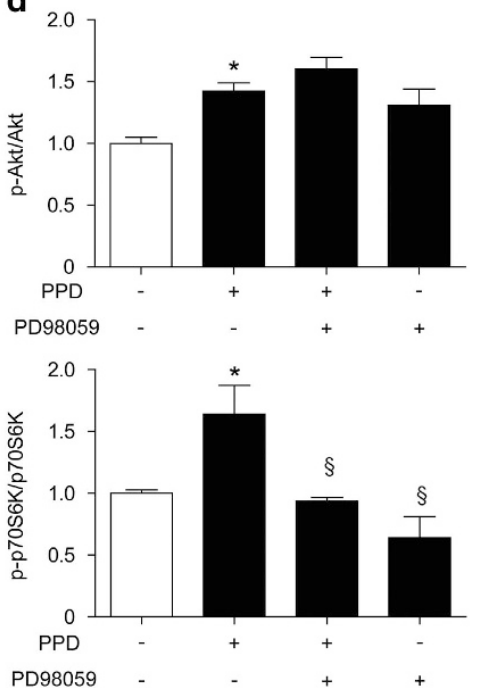
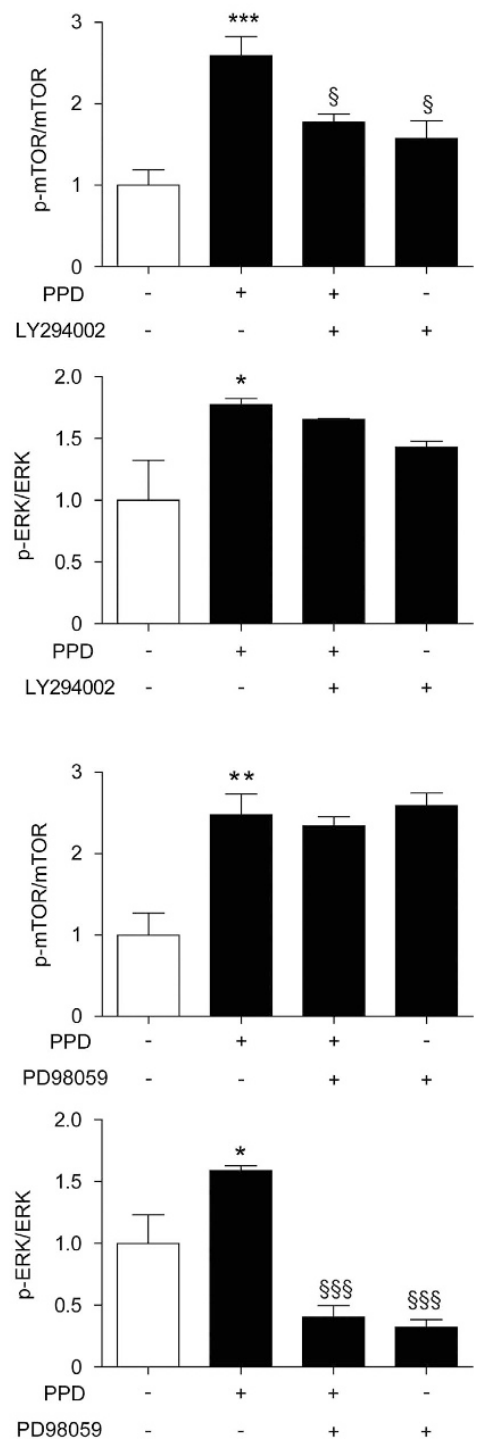

Figure 3 PPD-induced p70S6K phosphorylation was dependent on PI3K and ERK1/2 activation in HUVECs. (a, b) Phosphorylation of Akt, mTOR, p70S6K and ERK1/2, as well as the gray intensity analysis in HUVECs stimulated with PPD for $1 \mathrm{~h}$ following pre-treatment with LY294002 for 30 min. (c, d) Phosphorylation of PI3K, Akt, mTOR, p70S6K and ERK1/2, as well as the gray intensity analysis in HUVECs stimulated with PPD for $1 \mathrm{~h}$ following pre-treatment with PD98059 for $30 \mathrm{~min} . n=3$ per group. ${ }^{*} P<0.05,{ }^{* *} P<0.01$ and ${ }^{* * *} P<0.001$ versus control; ${ }^{\S} P<0.05,{ }^{\S \S} P<0.01$ and ${ }^{\S \S} P<0.001$ versus $P P D$ only.

concentration at $1 \mu \mathrm{M}$ (Figure $1 \mathrm{a}, P<0.01$ or $P<0.001$ ). Cell numbers of HUVECs were consistently elevated after PPD $(2.5 \mu \mathrm{M})$ stimulation (Figure $1 \mathrm{~b}, P<0.05$ or $P<0.01$ ). When used from 0.5 to $2.5 \mu \mathrm{M}, \mathrm{PPD}$ induced significant tube formation (Figure 1c-f). Compared with the control, PPD increased the number of tube networks in a concentrationdependent manner (Figure 1g, $P<0.05$ or $P<0.001$ ). Since PPD at $2.5 \mu \mathrm{M}$ had the best tube inductive effect, the concentration was used for the following experiments unless otherwise indicated. As shown in Figure 1h, PPD led to remarkable VEGF secretion after $48 \mathrm{~h}$ of treatment $(P<0.001)$. Moreover, PPD increased VEGF mRNA expression in a time-dependent manner (Figure 1i). These results demonstrated that PPD treatment enhanced VEGF expression at both the protein and mRNA levels and promoted angiogenesis in HUVECs.

Both the PI3K/Akt/mTOR/p70S6K and Raf/MEK/ERK signaling pathways were involved in PPD-induced angiogenic responses in HUVECs

Both the PI3K/Akt and Raf/MEK/ERK pathways are known to be actively involved in angiogenesis. ${ }^{21,22}$ Not surprisingly, after PPD stimulation, both pathways were significantly activated in HUVECs. As shown in Figure 2a, up-regulated phosphorylation of PI3K, Akt, c-Raf, MEK1/2 and ERK1/2 could be observed as early as $15 \mathrm{~min}$ after PPD stimulation and persisted for $4 \mathrm{~h}$. In addition, increased phosphorylation of mTOR and p70S6K, as well as the downstream signaling molecules of Akt, 
was also observed. To confirm the critical roles of the signaling pathways in PPD-induced angiogenesis, the PI3K inhibitor LY294002 and MEK1/2 inhibitor PD98059 were used. As shown in Figure 2b-i, PPD-induced cell proliferation, tube formation, and VEGF expression at the mRNA and protein levels were effectively abolished through the addition of the inhibitors. These results strongly indicated that PPD facilitated angiogenesis through these two pathways.

p70S6K played a critical role in PPD-induced angiogenesis As PPD activated both the PI3K/Akt and Raf/MEK/ERK pathways, whether these two pathways had interactive crosstalk was also investigated using the respective pathway inhibitors. As shown in Figure 3a and b, LY294002 simultaneously abrogated the increase of the phosphorylated Akt, mTOR and p70S6K induced by PPD. However, it failed to inhibit PPD-evoked ERK1/2 phosphorylation. On the other hand, PD98059 attenuated PPD-elicited phosphorylation of ERK1/2 and p70S6K without affecting Akt and mTOR (Figure 3c and d). However, both inhibitors deactivated p70S6K, which suggested that the PI3K/Akt/mTOR and Raf/MEK/ERK pathways had crosstalk via p70S6K.

To examine its role in PPD-induced angiogenic responses, p70S6K was silenced using the siRNA technique. A set of siRNAs for $p 70 S 6 \mathrm{~K}$ were pre-examined, and the one with the best interference efficacy was used for further experiments. As shown in Figure 4a, p70S6K siRNA effectively decreased cellular p70S6K protein expression. Accordingly, the proangiogenic effects of PPD were strongly inhibited in p70S6K knocked-down HUVECs, which was shown by reduced tube formation and cell proliferation, as well as down-regulated VEGF mRNA expression (Figure $4 \mathrm{~b}-\mathrm{h}$ ).

\section{PPD induced VEGF expression via activation of HIF-1 $\alpha$}

Expression of VEGF is regulated by many transcription factors, including HIF-1 $\alpha .{ }^{23}$ Under hypoxic or non-hypoxic conditions, the binding of HIF-1 $\alpha$ to the VEGF promoter is essential for the maximal transcription of VEGF mRNA. ${ }^{24-27}$ In this study, PPD increased VEGF secretion, as well as mRNA expression in HUVECs after a $48 \mathrm{~h}$ treatment (Figure $1 \mathrm{~h}$ and i). Not surprisingly, PPD also enhanced HIF-1 $\alpha$ production in HUVECs (Figure 5a and b). In addition, it facilitated the transfer of HIF-1 $\alpha$ from the cytoplasm to the nucleus in a time-dependent manner (Figure $5 \mathrm{a}$ and $\mathrm{c}$ ). Further study showed that PPD regulated HIF-1 $\alpha$ through the PI3K/Akt and MEK/ERK pathways as both LY294002 and PD98059 could effectively enhance cytoplasmic HIF- $1 \alpha$ but reduce nuclear HIF-1 $\alpha$ (Figure 5d and e). When silencing p70S6K from the cells using siRNA, PPD could not induce robust nuclear translocation of HIF- $1 \alpha$ any more (Figure $5 \mathrm{f}$ and g). Further ChIP analysis showed that PPD time-dependently increased the binding of activated HIF- $1 \alpha$ to the promoter of VEGF (Figure $5 \mathrm{~h}$ ). These results suggested that the activation of HIF- $1 \alpha$ by $p 70 S 6 \mathrm{~K}$ mediated a PPD-induced increase in VEGF expression.

\section{PPD stimulated neoangiogenesis in vivo}

To verify the pro-angiogenic properties of $\mathrm{PPD}$, an in vivo Matrigel plug assay was performed. Compared with the controls, PPD-infused Matrigel implants appeared to be redder in color (Figure 6a), which indicated that new blood vessel formation (angiogenesis) occurred in the plugs. Accordingly, the hemoglobin content in PPD-infused plugs increased significantly (Figure 6a). Moreover, as shown in Figure 6b-e, there was more $\mathrm{CD} 31^{+}$tube formation in PPD-treated Matrigels, which indicated that PPD had in vivo proangiogenic effects.

\section{PPD promoted wound healing in genetically diabetic mice} PPD treatment accelerated wound closure in $d b / d b$ mice (Figure 7a) compared with PBS treatment. Topical administration of different doses of PPD $\left(0.6,6\right.$ and $\left.60 \mathrm{mg} \mathrm{ml}^{-1}\right)$ contributed variably to wound healing. On days 8 and 14 post-injury, wound areas treated with higher doses of PPD (6 and $60 \mathrm{mg} \mathrm{ml}^{-1}$ ) were significantly narrower (Figure 7b and c, $P<0.001)$. Representative pictures of the wounds at 8 , 12 and 14 days post-injury clearly showed that the epithelium of the PPD-treated wounds grew faster compared to PBStreated controls (Figure 7d). The histological evaluation of diabetic wounds was consistent with the increased closure rate of the PPD-treated wounds. The epithelial gaps in PPD-treated wounds on days 7 and 10 post-injury were reduced markedly in contrast to PBS-treated controls (Figure 7e and f, $P<0.01$ and $P<0.05$ ).

Since VEGF plays an important role in wound healing and previous studies have indicated that PPD could up-regulate VEGF production in HUVECs, the mRNA and protein expression levels of VEGF were measured in the wound samples. Similar to its in vitro effect, PPD treatment led to significant VEGF expression at both the mRNA and protein levels on days 7 and 14 post-injury (Figure 8a-c). CD31 expression at the protein level in the wounds was also elevated by PPD on days 7 and 14 post-injury (Figure $8 \mathrm{~b}$ and d). In addition, as shown in Figure 8e and $\mathrm{f}$, PPD-treated wounds included more CD31-immunoreactive capillary vessels $(P<0.001)$. And the phosphorylation of PI3K/Akt/ERK/ p70S6K, as well as HIF-1 $\alpha$ was enhanced by PPD in the wounds on day 7 post-injury (Figure $8 \mathrm{~g}$ and $\mathrm{h}, P<0.05$ or $P<0.01$ ). All these results strongly implicated that PPD treatment promoted angiogenesis and benefited wound healing in diabetic mice.

\section{DISCUSSION}

Wound healing is a complex, dynamic and orderly controlled process in which angiogenesis or neovascularization plays a crucial pathophysiological role by nourishing newly formed tissues. ${ }^{5,6}$ Many natural products, such as propolis, ${ }^{28,29}$ bee venom, ${ }^{30}$ whey protein ${ }^{31}$ and curcumin, ${ }^{32}$ have been shown to be beneficial to diabetic wound healing. In this study, our results showed that PPD, another natural product from $P$. ginseng, promoted angiogenesis in vitro through HIF- $1 \alpha-$ mediated VEGF secretion by activating p70S6K. In addition, 

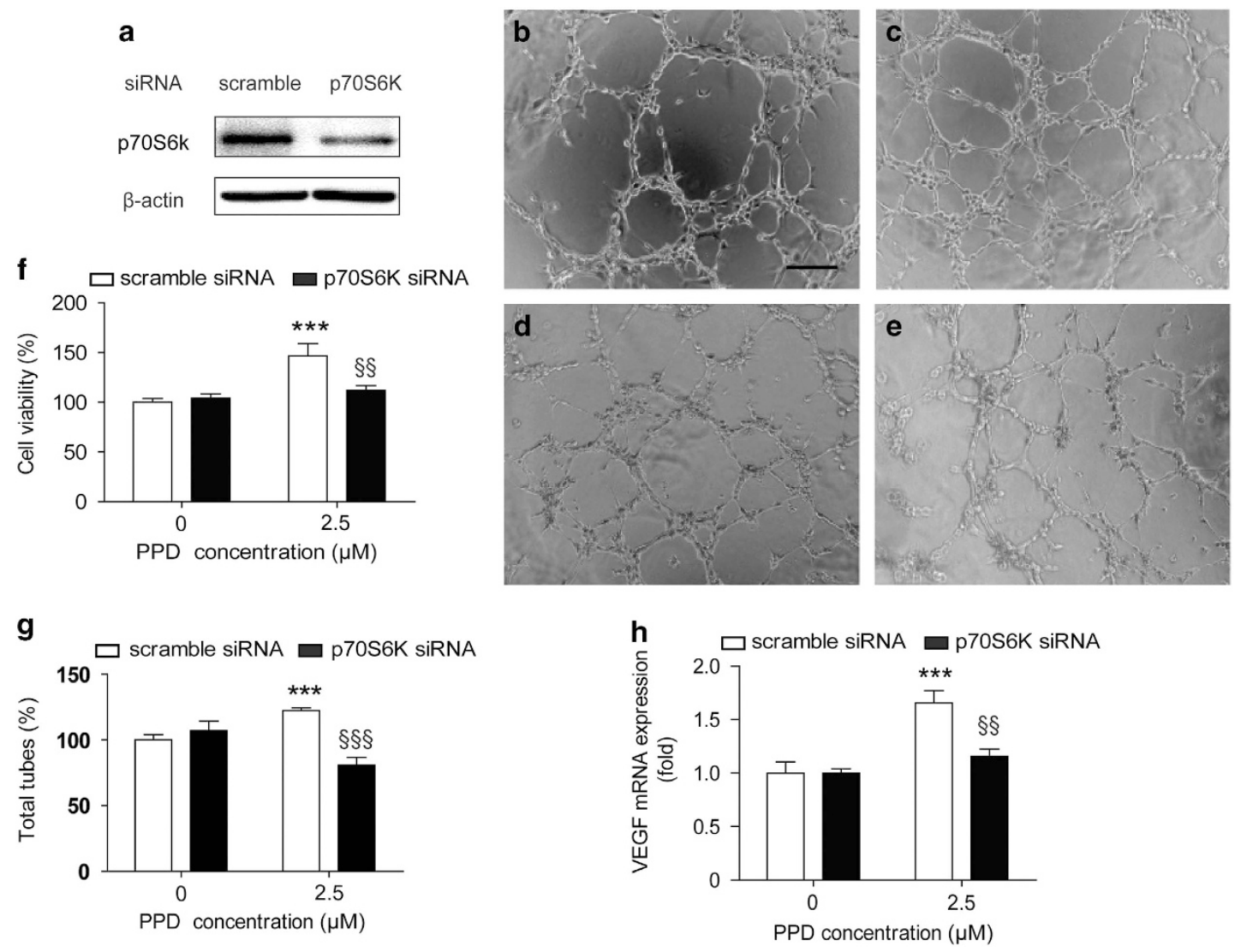

Figure 4 p70S6K played a critical role in PPD-induced angiogenesis in HUVECs. HUVECs were transiently transfected with p70S6K. (a) Examination of transfection efficiency by western blot. (b-e) Tube formation activity. (b) Scramble siRNA; (c) Scramble siRNA+ PPD $(2.5 \mu \mathrm{m})$; (d) $p 70 S 6 \mathrm{~K}$ siRNA; (e) $p 7056 \mathrm{~K}$ siRNA+ PPD $(2.5 \mu \mathrm{m})$. (f) Cell viability upon PPD stimulation for $48 \mathrm{~h}$. $n=6$ per group. (g) Number of tubes formed after PPD stimulation for 4 h. $n=6$ /group. (h) VEGF mRNA expression after PPD stimulation for 24 h. $n=6$ per group. ${ }^{* *} P<0.001$ versus scramble siRNA; ${ }^{\S \S} P<0.01$ and ${ }^{\S \S \S} P<0.001$ versus scramble siRNA stimulated with PPD.

in an excisional wound splinting model in $d b / d b$ mice, ${ }^{11,33} \mathrm{PPD}$ accelerated the wound healing process with prominently enhanced angiogenesis, which indicated that PPD has potential use in treating DFUs.

Proliferation and tube formation of endothelial cells indicate the sprouting of new blood vessels from existing vascular structures in angiogenesis, ${ }^{34,35}$ which are promoted through many pro-angiogenic growth factors such as VEGF, bFGF and PDGF. ${ }^{36-39}$ In cultured HUVECs, our study showed that PPD induced robust proliferation and tube formation accompanied by elevated VEGF, bFGF and PDGF production at either the mRNA or protein level (unpublished data). VEGF exerts its biological functions by binding to transmembrane receptors, such as VEGFR1 and VEGFR2, both of which are specifically expressed on the surfaces of endothelial cells and contain a cytoplasmic tyrosine kinase domain. ${ }^{40}$ Interestingly, we found that PPD substantially up-regulated the phosphorylation of VEGFR2 in HUVECs (unpublished data), which indicated that the pro-angiogenic effects of PPD may be partially mediated through VEGR2 activation. In agreement with the in vitro experiments, PPD also promoted angiogenesis in Matrigel plugs and diabetic wounds, such as the biomarker for blood vessels CD31, which was elevated significantly along with VEGF (Figure 7a), bFGF and PDGF production (Supplementary Figure S2). The consistent in vivo and in vitro effects suggested that PPD has a pro-angiogenic function.

VEGF is one of the most potent angiogenic factors promoting all stages of angiogenesis. ${ }^{37,38}$ It is highly specific for endothelial cells and likely to act on the sprouting blood vessels of the wound edge in a paracrine manner. ${ }^{36}$ VEGF gene expression can be modulated at the transcriptional level, and the VEGF promoter contains various binding sites for transcription factors, including HIF- $1 \alpha$ and STAT3 ${ }^{23,41}$ Many studies suggested that constitutive STAT3 activation upregulates VEGF expression and enhances angiogenesis. ${ }^{41-43}$ Interestingly, PPD treatment induced JAK/STAT3 phosphorylation in a time-dependent manner (Supplementary Figure S4), which suggests that the pathway was actively involved in the promotion of PPD on angiogenesis. The binding of HIF- $1 \alpha$ to the VEGF promoter is essential for the maximal transcription of VEGF mRNA. ${ }^{24-27}$ In the present study, PPD facilitated the transport of HIF- $1 \alpha$ from the cytoplasm to the nucleus. Further ChIP analysis showed that PPD could time-dependently induce the binding of HIF- $1 \alpha$ to the VEGF promoter, which suggests that PPD increased VEGF production through modulation of HIF- $1 \alpha$. 
a

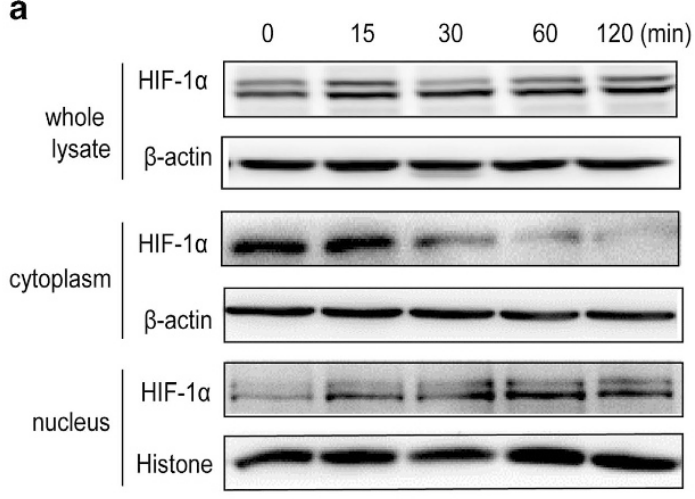

d

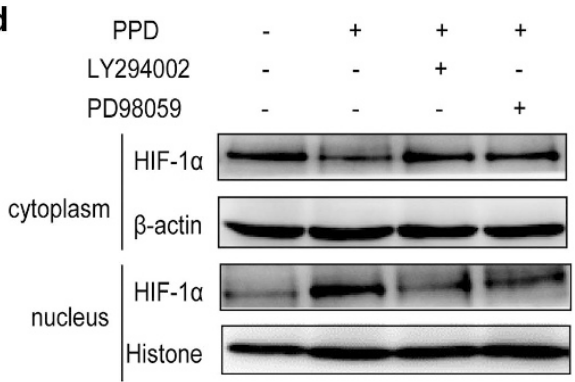

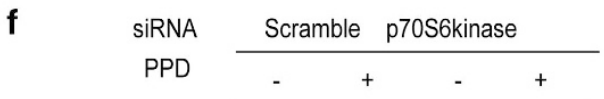
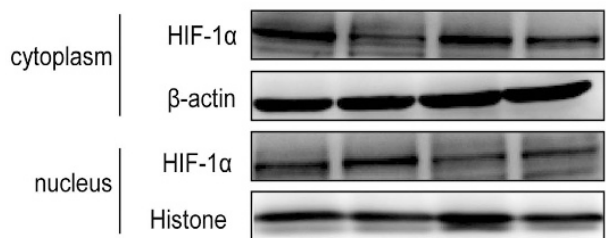

\section{g}

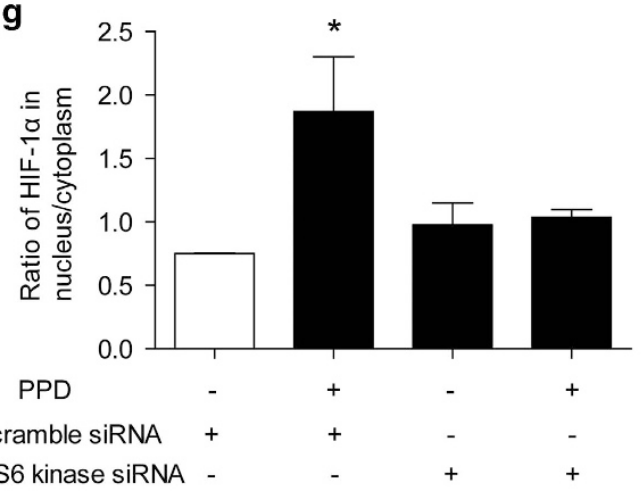

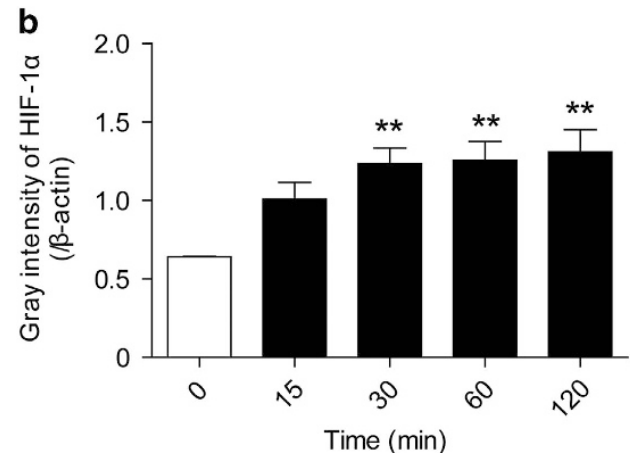

c

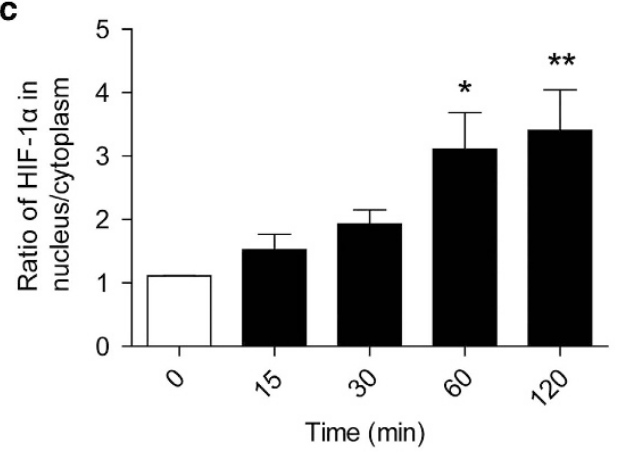

e

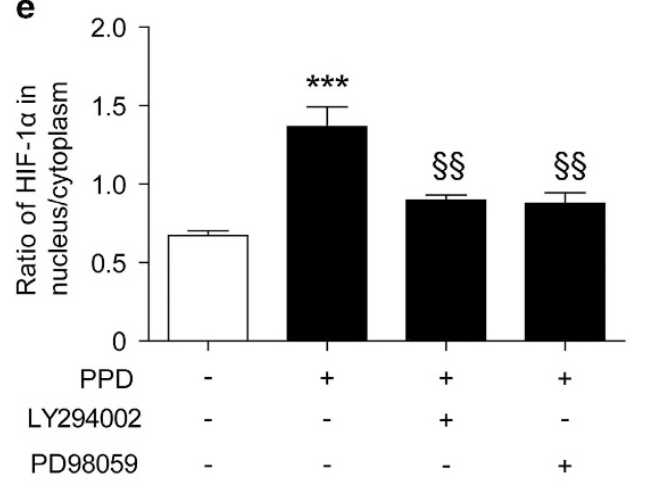

h

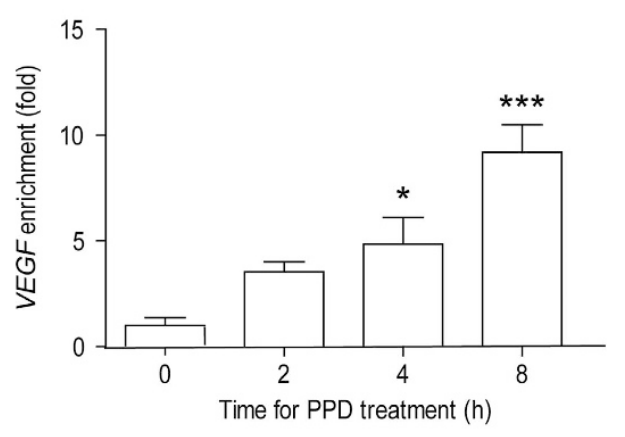

Figure 5 PPD modulated VEGF expression through HIF-1 $\alpha$ in HUVECs. (a-c) Western blotting and gray intensity analysis of the transport of HIF-1 $\alpha$ from the cytoplasm to the nuclei after PPD stimulation. $n=5$ per group. (d, e) Western blotting and gray intensity analysis of the transport of HIF-1 $\alpha$ from the cytoplasm to the nuclei after PPD stimulation for $2 \mathrm{~h}$ following pre-treatment with LY294002 or PD98059 for 30 min. $n=5$ per group. (f, g) Western blotting and gray intensity analysis of the transport of HIF-1 $\alpha$ from the cytoplasm to the nuclei after PPD stimulation for $2 \mathrm{~h}$ in p70S6K -silenced HUVECs. $n=5 /$ group. (h) ChIP assay for interaction of HIF- $1 \alpha$ and the VEGF promoter. $n=6$ per group. ${ }^{*} P<0.05$ and ${ }^{* *} P<0.001$ versus control, ${ }^{\S \S} P<0.01$ versus PPD only. 
a

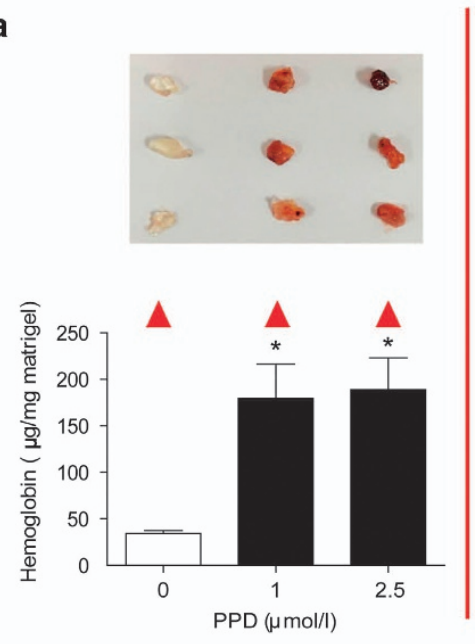

b
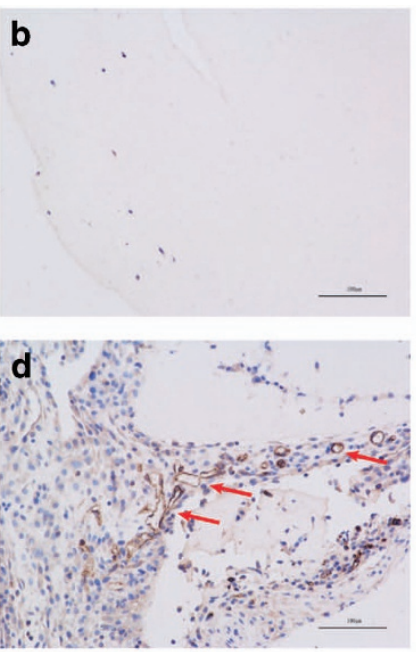
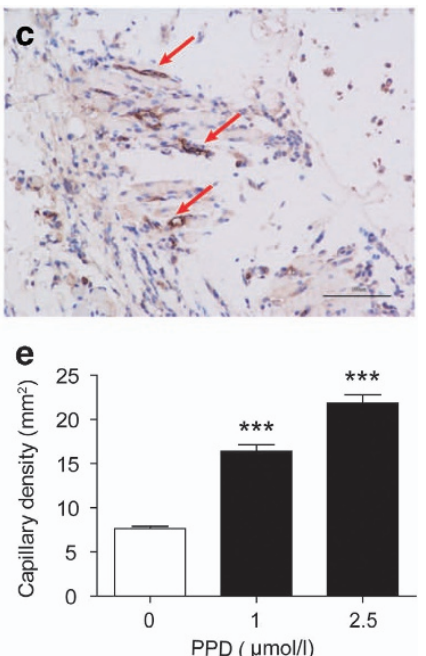

Figure 6 PPD stimulated neoangiogenesis in C57BL/6 mice. (a) PPD-infused Matrigel plugs included more hemoglobin after a one-week implantation. (b-e) Immunostaining of CD31 in PPD-treated Matrigel plugs. (b) PPD $0 \mu \mathrm{M}$; (c) PPD $1 \mu \mathrm{M}$; (d) PPD $2.5 \mu \mathrm{M}$; (e) Capillary density of PPD-treated Matrigel plugs. ${ }^{*} P<0.05$ and ${ }^{* * *} P<0.001$ versus control, $n=5$ per group.

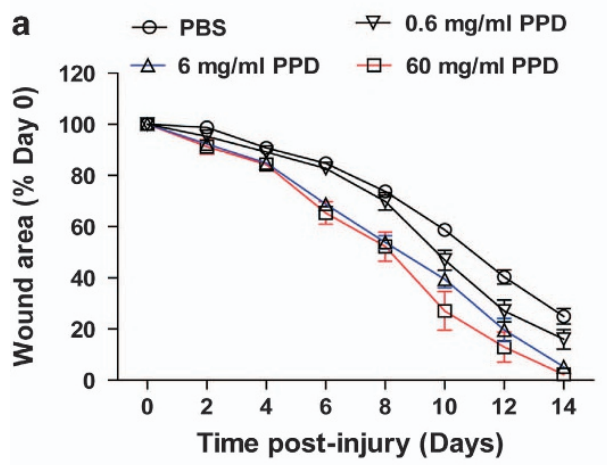

e

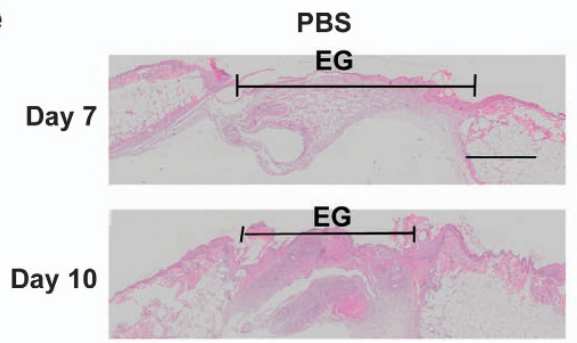

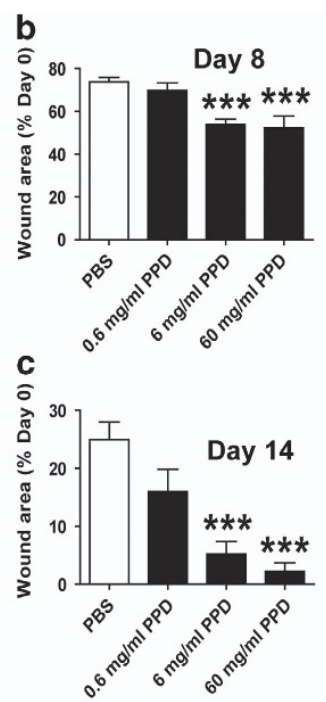
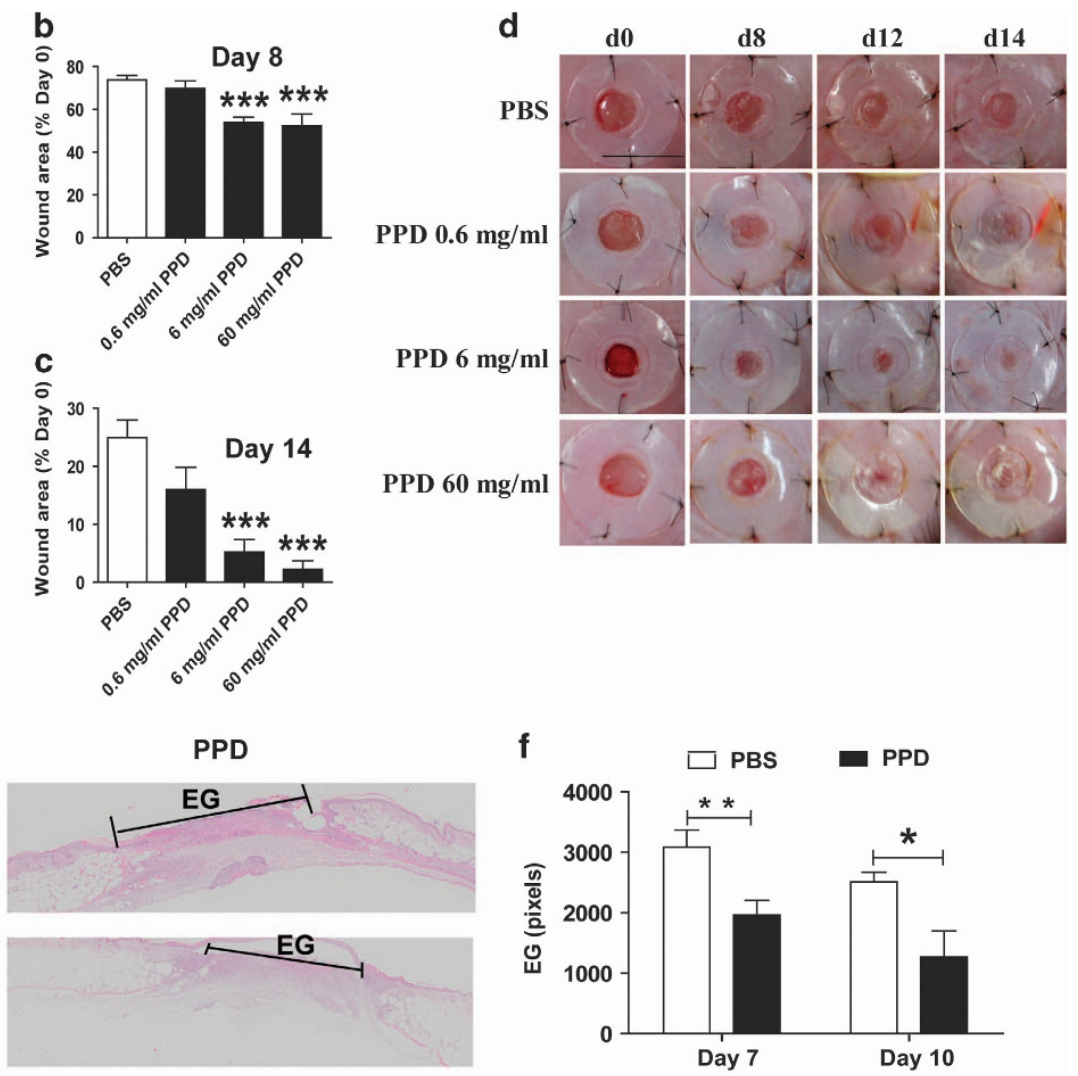

Figure 7 PPD benefited wound healing in $d b / d b$ mice. (a) Wound closure curve in wounds treated with PPD. $n=16$ per group. (b, c) Comparison of the wound area on days 8 and 14 post-injury. $n=16$ per group. (d) Representative pictures of wounds on days 8,12 and 14 post-injury. Scale bar $=10 \mathrm{~mm}$. (e) HE staining of wounds on days 7 and 10 post-injury. Scale bar $=1 \mathrm{~mm}$. (f) PPD induced faster closure of the epithelial gap. $n=6$ per group. ${ }^{*} P<0.05$ and ${ }^{* *} P<0.01$ versus control. EG, Epithelial gap.

Our next question was to uncover the way that PPD modulated the activation of HIF-1 $\alpha$. Both the PI3K/Akt and Raf/MEK/ERK pathways significantly contribute to angiogenesis during wound healing. ${ }^{21,44-46}$ Our findings showed that
PPD accelerated the phosphorylation of PI3K/Akt $/ \mathrm{mTOR} /$ p70S6K/Raf/MEK/ERK in a time-dependent manner, which suggested that both the PI3K/Akt and MEK/ERK pathways were actively involved in the angiogenic responses induced by 


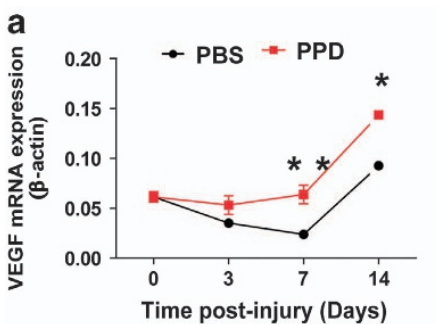

e

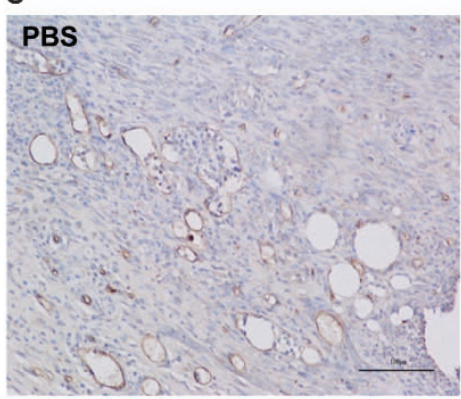

b

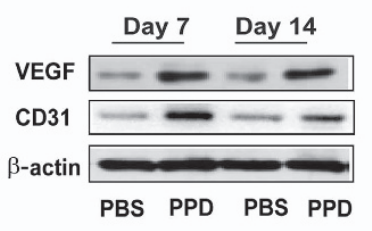

C

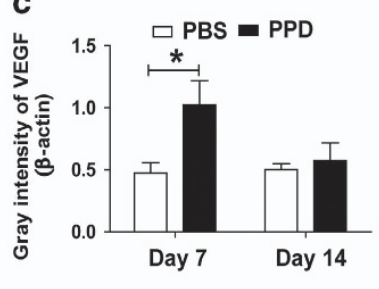

d

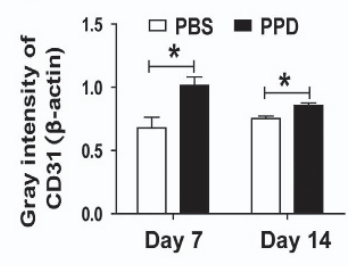

f
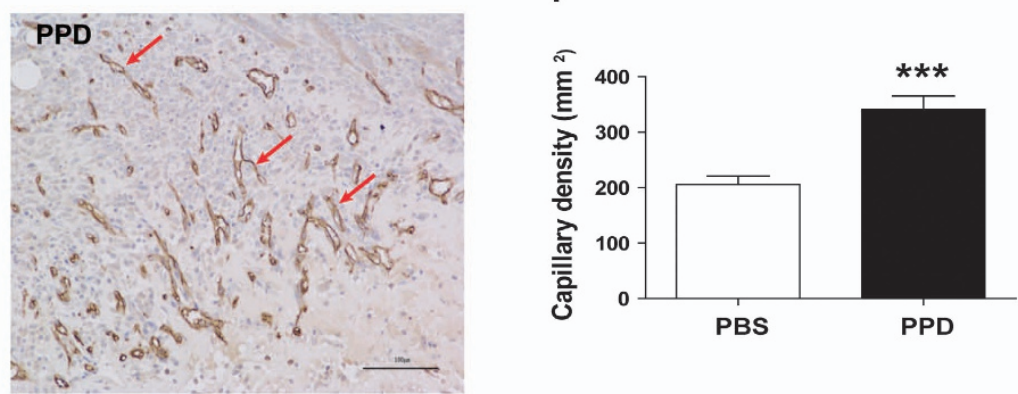

g
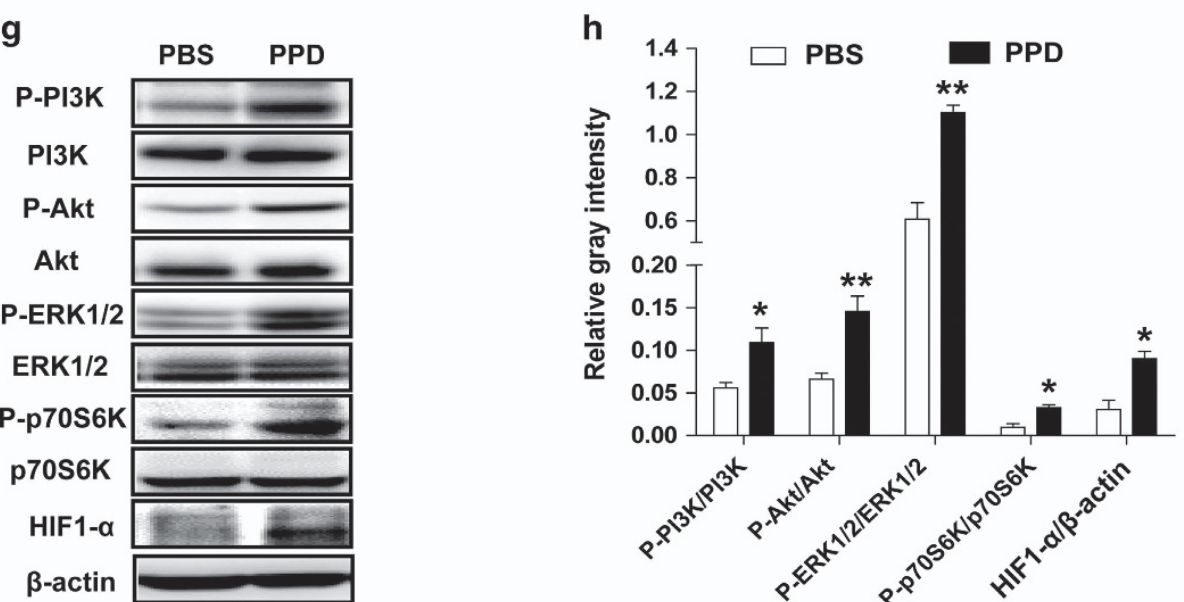

Figure 8 PPD induced neoangiogenesis in wounds of $d b / d b$ mice. (a) mRNA expression levels of VEGF in wounds on days 3,7 and 14 post-injury. $n=6$ per group. (b) Representative bands of VEGF and CD31 in PBS- or PPD-treated wounds. Gray intensity analysis of VEGF (c) and CD31 (d). $n=5 /$ group. (e) Immunostaining of CD31. Scale bar $=100 \mu \mathrm{m}$. (f) Capillary intensity analysis. (g) Western blotting analysis of the molecules in wounds treated with PPD $\left(6 \mathrm{mg} \mathrm{ml}^{-1}\right)$ on day 7 post-injury. (h) Gray intensity analysis. PPD was used at $6 \mathrm{mg} \mathrm{ml}^{-1}$. ${ }^{*} P<0.05$ and ${ }^{*} P P<0.01$ versus control.

PPD. However, these two pathways seemed to be independent from each other since the inhibitor of one pathway could not abrogate the activation of the other one. Fortunately, further investigation showed that these two pathways had crosstalk through p70S6K because both LY294002 and PD98059 could efficiently block the activation of kinases. Previous studies suggested that $\mathrm{p} 70 \mathrm{~S} 6 \mathrm{~K}$ is required for angiogenesis under both in vitro and in vivo conditions and involves both VEGF and HIF- $1 \alpha$ expression. ${ }^{24}$ Our study showed that silencing p70S6K activity resulted in the inhibition of PPD-induced proangiogenic responses, including increases in HIF- $1 \alpha$ activity and VEGF secretion. Consistent with the in vitro studies, PPD treatment enhanced the signaling of PI3K/Akt/ERK/p70S6K associated with up-regulated HIF- $1 \alpha$ expression in diabetic wounds. These observations implied that p70S6K played an important role in the pro-angiogenic activities of PPD.
Fibroblasts in the granulation of wound tissues are responsible for most collagen synthesis and organization of the ECM components, ${ }^{47}$ which contribute to wound healing through secretion of various growth factors that facilitate angiogenesis and matrix deposition. ${ }^{48}$ In the current study, PPD treatment significantly enhanced the composition of mature collagen in diabetic wounds (Supplementary Figure S2). Moreover, PPD treatment increased the mRNA expression of bFGF, PDGF, fibronectin, and collagen (CoL1A1, CoL1A2 and CoL3A1) in diabetic wound beds and promoted human fibroblast proliferation in vitro. These results implied that PPD stimulated collagen synthesis by enhancing the proliferation of fibroblasts in diabetic wounds.

Excessive inflammation shown by infiltration of neutrophils is a consistent feature of diabetes-impaired wound healing. ${ }^{49}$ In the current study, topical PPD treatment decreased 
inflammatory cell infiltration in diabetic wound beds associated with reduced levels of the pro-inflammatory cytokines/chemokines IL-6, TNF- $\alpha$, CD45, CXCL5 and CXCL11 (Supplementary Figure S3) in diabetic wounds. Meanwhile, PPD reduced LPS-stimulated nitric oxide production in the macrophage cell line RAW264.7 and high glucose induced mRNA expression of CXCL5 and CXCL11 in HUVECs. These results implied that PPD could inhibit inflammation in diabetic wounds.

Taken together, we demonstrated that PPD promoted angiogenesis through a HIF- $1 \alpha$-mediated increase in VEGF production and that p70S6K activation occurred through both the PI3K/Akt/mTOR and Raf/MEK/ERK pathways. Furthermore, PPD accelerated wound healing in diabetic mice, which was probably orchestrated by promoting angiogenesis and collagen synthesis, as well as preventing inflammation. Our results suggest that there is a promising application for PPD in the clinical treatment of DFUs.

\section{CONFLICT OF INTEREST}

The authors declare no conflict of interest.

\section{ACKNOWLEDGEMENTS}

This work was financially supported by the National Natural Science Foundation of China (81530096 and 81673626), the Shanghai ThreeYear Plan for Advancing Traditional Medicine (ZY3-CCCX-3-3014), the Shanghai Eastern Scholar Program (2013-59) and the Shanghai E-research Institute of Bioactive Constituent in TCM plan.

1 Brantley JN, Verla TD. Use of placental membranes for the treatment of chronic diabetic foot ulcers. Adv Wound Care 2015; 4: 545-559.

2 Reiber GE, Vileikyte L, Boyko EJ, del Aguila M, Smith DG, Lavery LA et al. Causal pathways for incident lower-extremity ulcers in patients with diabetes from two settings. Diabetes Care 1999; 22: 157-162.

3 Ramsey SD, Sandhu N, Newton K, Reiber GE, Blough D, Wagner EH et al. Incidence, outcomes, and cost of foot ulcers in patients with diabetes. Diabetes Care 1999; 22: 382-387.

4 Boulton AJM, Vileikyte L, Ragnarson-Tennvall G, Apelqvist J. The global burden of diabetic foot disease. Lancet 2005; 366: 1719-1724.

5 Falanga V. Wound healing and its impairment in the diabetic foot. Lancet 2005; 366: 1736-1743.

6 Martin P. Wound healing-aiming for perfect skin regeneration. Science 1997; 276: 75-81.

7 Adams $\mathrm{RH}$, Alitalo $\mathrm{K}$. Molecular regulation of angiogenesis and lymphangiogenesis. Nat Rev Mol Cell Biol 2007; 8: 464-478.

8 Yancopoulos GD, Davis S, Gale NW, Rudge JS, Wiegand SJ, Holash J. Vascular-specific growth factors and blood vessel formation. Nature 2000; 407: 242-248.

9 Park HJ, Zhang Y, Georgescu SP, Johnson KL, Kong D, Galper JB. Human umbilical vein endothelial cells and human dermal microvascular endothelial cells offer new insights into the relationship between lipid metabolism and angiogenesis. Stem Cell Rev 2006; 2: 93-102.

10 Wang X, Ge J, Tredget EE, Wu Y. The mouse excisional wound splinting model, including applications for stem cell transplantation. Nat Protoc 2013; 8: 302-309.

11 Galiano RD, Michaels Jt, Dobryansky M, Levine JP, Gurtner GC. Quantitative and reproducible murine model of excisional wound healing. Wound Repair Regen 2004; 12: 485-492.

12 Mao Q, Li Y, Li S, Yang J, Zhang P, Wang Q. Chemical profiles and anticancer effects of saponin fractions of different polarity from the leaves of Panax notoginseng. Chin J Nat Med 2014; 12: 30-37.
13 Kawahira K, Sumiyoshi M, Sakanaka M, Kimura Y. Effects of ginsenoside Rb1 at low doses on histamine, substance $P$, and monocyte chemoattractant protein 1 in the burn wound areas during the process of acute burn wound repair. J Ethnopharmacol 2008; 117: 278-284.

14 Kwok HH, Guo GL, Lau JK, Cheng YK, Wang JR, Jiang ZH et al. Stereoisomers ginsenosides-20(S)- $\mathrm{Rg}_{3}$ and $-20(\mathrm{R})-\mathrm{Rg}_{3}$ differentially induce angiogenesis through peroxisome proliferator-activated receptor-gamma. Biochem Pharmacol 2012; 83: 893-902.

15 Cho YL, Hur SM, Kim JY, Kim JH, Lee DK, Choe J et al. Specific activation of insulin-like growth factor-1 receptor by ginsenoside Rg5 promotes angiogenesis and vasorelaxation. J Biol Chem 2015; 290: 467-477.

16 Shen K, Ji L, Gong C, Ma Y, Yang L, Fan Y et al. Notoginsenoside Ft1 promotes angiogenesis via HIF-1alpha mediated VEGF secretion and the regulation of PI3K/AKT and Raf/MEK/ERK signaling pathways. Biochem Pharmacol 2012; 84: 784-792.

17 Shen KK, Leung SWS, Ji LL, Huang Y, Hou MQ, Xu AM et al. Notoginsenoside Ft1 activates both glucocorticoid and estrogen receptors to induce endothelium-dependent, nitric oxide-mediated relaxations in rat mesenteric arteries. Biochem Pharmacol 2014; 88: 66-74.

18 Jeong $\mathrm{A}$, Lee $\mathrm{HJ}$, Jeong SJ, Lee HJ, Lee EO, Bae $\mathrm{H}$ et al. Compound $\mathrm{K}$ inhibits basic fibroblast growth factor-induced angiogenesis via regulation of p38 mitogen activated protein kinase and AKT in human umbilical vein endothelial cells. Bio Pharm Bull 2010; 33: 945-950.

19 Usami Y, Liu YN, Lin AS, Shibano M, Akiyama T, Itokawa H et al. Antitumor agents. 261. 20(S)-protopanaxadiol and 20(s)-protopanaxatriol as antiangiogenic agents and total assignment of (1)H NMR spectra. J Nat Prod 2008; 71: 478-481.

20 Zhang E, Gao B, Yang L, Wu X, Wang Z. Notoginsenoside Ft1 promotes fibroblast proliferation via PI3K/Akt/mTOR signaling pathway and benefits wound healing in genetically diabetic mice. J Pharmacol Exp Ther 2016; 356: 324-332.

21 Bader AG, Kang S, Zhao L, Vogt PK. Oncogenic PI3K deregulates transcription and translation. Nat Rev Cancer 2005; 5: 921-929.

22 Hood JD, Frausto R, Kiosses WB, Schwartz MA, Cheresh DA. Differential alphav integrin-mediated Ras-ERK signaling during two pathways of angiogenesis. J Cell Biol 2003; 162: 933-943.

23 Pages G, Pouyssegur J. Transcriptional regulation of the vascular endothelial growth factor gene-a concert of activating factors. Cardiovasc Res 2005; 65: 564-573.

24 Shweiki D, Itin A, Soffer D, Keshet E. Vascular endothelial growth factor induced by hypoxia may mediate hypoxia-initiated angiogenesis. Nature 1992; 359: 843-845.

25 Gray MJ, Zhang J, Ellis LM, Semenza GL, Evans DB, Watowich SS et al. HIF-1alpha, STAT3, CBP/p300 and Ref-1/APE are components of a transcriptional complex that regulates Src-dependent hypoxia-induced expression of VEGF in pancreatic and prostate carcinomas. Oncogene 2005; 24: 3110-3120.

26 Zelzer E, Levy Y, Kahana C, Shilo BZ, Rubinstein M, Cohen B. Insulin induces transcription of target genes through the hypoxia-inducible factor HIF-1alpha/ARNT. EMBO J 1998; 17: 5085-5094.

27 Bilton RL, Booker GW. The subtle side to hypoxia inducible factor (HIFalpha) regulation. Eur J Biochem 2003; 270: 791-798.

28 Badr G. Supplementation with undenatured whey protein during diabetes mellitus improves the healing and closure of diabetic wounds through the rescue of functional long-lived wound macrophages. Cell Physiol Biochem 2012; 29: 571-582.

$29 \mathrm{Badr}$ G. Camel whey protein enhances diabetic wound healing in a streptozotocin-induced diabetic mouse model: the critical role of beta-Defensin-1, -2 and -3. Lipids Health Dis 2013; 12: 46.

30 Badr G, Hozzein WN, Badr BM, Al Ghamdi A, Saad Eldien HM, Garraud O. Bee venom accelerates wound healing in diabetic mice by suppressing activating transcription factor-3 (ATF-3) and inducible nitric oxide synthase (iNOS)-mediated oxidative stress and recruiting bone marrow-derived endothelial progenitor cells. J Cell Physiol 2016; 231: 2159-2171.

31 Hozzein WN, Badr G, Al Ghamdi AA, Sayed A, Al-Waili NS, Garraud 0. Topical application of propolis enhances cutaneous wound healing by promoting TGF-beta/Smad-mediated collagen production in a streptozotocin-induced type I diabetic mouse model. Cell Physiol Biochem 2015; 37: 940-954.

32 Kant V, Gopal A, Kumar D, Pathak NN, Ram M, Jangir BL et al. Curcumin-induced angiogenesis hastens wound healing in diabetic rats. J Surg Res 2015; 193: 978-988. 
33 Jacobi J, Jang JJ, Sundram U, Dayoub H, Fajardo LF, Cooke JP. Nicotine accelerates angiogenesis and wound healing in genetically diabetic mice. Am J Pathol 2002; 161: 97-104.

34 Holash J, Wiegand SJ, Yancopoulos GD. New model of tumor angiogenesis: dynamic balance between vessel regression and growth mediated by angiopoietins and VEGF. Oncogene 1999; 18: 5356-5362.

35 Lamalice L, Le Boeuf F, Huot J. Endothelial cell migration during angiogenesis. Circ Res 2007; 100: 782-794.

36 Altavilla D, Saitta A, Cucinotta D, Galeano M, Deodato B, Colonna M et al. Inhibition of lipid peroxidation restores impaired vascular endothelial growth factor expression and stimulates wound healing and angiogenesis in the genetically diabetic mouse. Diabetes 2001; 50: 667-674.

37 Przybylski M. A review of the current research on the role of bFGF and VEGF in angiogenesis. J Wound Care 2009; 18: 516-519.

38 Bao P, Kodra A, Tomic-Canic M, Golinko MS, Ehrlich HP, Brem H. The role of vascular endothelial growth factor in wound healing. J Surg Res 2009; 153: 347-358

39 Odorisio T, Cianfarani F, Failla CM, Zambruno G. The placenta growth factor in skin angiogenesis. J Dermatol Sci 2006; 41: 11-19.

40 Stotz M, Gerger A, Haybaeck J, Kiesslich T, Bullock MD, Pichler M. Molecular targeted therapies in hepatocellular carcinoma: past, present and future. Anticancer Res 2015; 35: 5737-5744.

41 Jung JE, Lee HG, Cho IH, Chung DH, Yoon SH, Yang YM et al. STAT3 is a potential modulator of HIF-1-mediated VEGF expression in human renal carcinoma cells. FASEB J 2005; 19: 1296-1298.

42 Xue C, Xie J, Zhao D, Lin S, Zhou T, Shi S et al. The JAK/STAT3 signalling pathway regulated angiogenesis in an endothelial cell/adipose-derived stromal cell co-culture, 3D gel model. Cell Prolif 2017; 50: e12307.

43 Niu G, Wright KL, Huang M, Song L, Haura E, Turkson J et al. Constitutive Stat3 activity up-regulates VEGF expression and tumor angiogenesis. Oncogene 2002; 21: 2000-2008.

44 Han G, Li F, Ten Dijke P, Wang XJ. Temporal smad7 transgene induction in mouse epidermis accelerates skin wound healing. Am J Pathol 2011; 179: 1768-1779.
45 Chim SM, Qin A, Tickner J, Pavlos N, Davey T, Wang H et al. EGFL6 promotes endothelial cell migration and angiogenesis through the activation of extracellular signal-regulated kinase. J Biol Chem 2011; 286: 22035-22046.

46 Kim WS, Yang YJ, Min HG, Song MG, Lee JS, Park KY et al. Accelerated wound healing by S-methylmethionine sulfonium: evidence of dermal fibroblast activation via the ERK1/2 pathway. Pharmacology 2010; 85: 68-76.

47 Mansbridge JN, Liu K, Pinney RE, Patch R, Ratcliffe A, Naughton GK. Growth factors secreted by fibroblasts: role in healing diabetic foot ulcers. Diabetes Obes Metab 1999; 1: 265-279.

48 Al-Mulla F, Leibovich SJ, Francis IM, Bitar MS. Impaired TGF-beta signaling and a defect in resolution of inflammation contribute to delayed wound healing in a female rat model of type 2 diabetes. Mol Biosyst 2011; 7: 3006-3020.

49 Eming SA, Krieg T, Davidson JM. Inflammation in wound repair: molecular and cellular mechanisms. J Invest Dermatol 2007; 127: 514-525.

(c) (1) $\Theta$ This work is licensed under a Creative Commons Attribution-NonCommercial-NoDerivs

4.0

International License. The images or other third party material in this article are included in the article's Creative Commons license, unless indicated otherwise in the credit line; if the material is not included under the Creative Commons license, users will need to obtain permission from the license holder to reproduce the material. To view a copy of this license, visit http://creativecommons.org/licenses/by-nc-nd/4.0/

(C) The Author(s) 2017

Supplementary Information accompanies the paper on Experimental \& Molecular Medicine website (http://www.nature.com/emm) 